\title{
Transfollicular Drug Delivery Systems
}

\author{
Anayatollah Salimi ${ }^{1,2}$ and Saeed Mohammad Soleymani ${ }^{2,{ }^{*}}$ \\ ${ }^{1}$ Nanotechnology Research Center, Ahvaz Jundishapur University of Medical Sciences, Ahvaz, Iran \\ ${ }^{2}$ Department of Pharmaceutics, Ahvaz Jundishapur University of Medical Sciences, Ahvaz, Iran \\ "Corresponding author: Department of Pharmaceutics, Ahvaz Jundishapur University of Medical Sciences, Ahvaz, Iran. Tel/Fax: +98-9128476977, Email: mamsoloni@gmail.com
}

Received 2018 July 19; Revised 2018 July 25; Accepted 2018 July 28.

Keywords: Transfollicular, Drug Delivery, Hair Follicle, Nanoencapsulation, Foam, Liposome, Microemulsion

The hair follicle is an organ in the human skin. This organ consists of about 20 cell types. Hair follicles regulate hair growth with hormones, neuroproteins, and immune cells. This complex interaction leads to the production of different hair by hair follicles seen on different parts of the body. The stages of hair growth are: Anagen (active growth stage), Catagen (rest stage), Telogen (regression phase of the hair follicle), Exogen (active phase of hair erosion), and finally Kenogen (the time between hair follicle being empty and new hair growth) (1).

The hair follicle includes hair roots and sebaceous glands. This structure inside the skin has a certain biochemistry, metabolism, and immunology. Recent studies have focused on hair follicles as a potential route for delivery of topical and systemic drugs (2). Drug delivery through hair follicles is very important because it has optimal effects on the delivery of topical medications. These follicles are enclosed by capillaries, antigen-containing cells, sebaceous glands, and stem cells in the extremity of the hair follicles (3). Hair follicles and sebaceous glands can be specific pathways for the passage of certain molecules or formulations that enter the site of effect or blood faster than the stratum corneum (4).

The immunological environment of the hair follicles has recently been addressed by researchers in the field of transfollicular delivery, in particular for the development of active immune function without needle insertion. Hair follicles may facilitate the absorption of large molecules or hydrophilic molecules, such as vaccine antigens. Nanotechnology may facilitate transfollicular in various ways, as nanoparticles penetrate more in hair follicles. Also, nanoencapsulation can stabilize the antigens and increase their antigenicities. It seems that only a limited portion of the antigen should be available locally through the hair follicles (5).

The use of formulations, such as foam, can also in- crease the absorption of drugs by transfollicular treatment. A study on the absorption of minoxidil showed that minoxidil foam brings the drug through the hair follicle better than the stratum corneum pathway. This study suggests that higher absorption from the follicular route is due to the presence of a dense network of hair follicles by a dense network of blood capillaries, dendritic cells and stem cells, which is very suitable for drug delivery (6).

Many studies have shown that drug permeation with a microemulsion formulation may be increased by transfollicular administration (7). Microemulsions are transparent semi-solid drug delivery systems with high hermodynamic stability, which include isotropic liquid, oil, water and surfactant mixtures, usually combined with a carbohydrate compound $(8,9)$. The particle size of the dispersed phase in a microemulsion is less than $100 \mathrm{~nm}$. Microemulsions primarily increase drug local absorption (1012). Trans-follicular transfusion adapalene examination shows that microemulsions penetrates through hair follicles and is suitable for delivery of a transfollicular drug (7).

Liposomes have been used extensively for drug delivery in several studies. Studies have shown that liposomes have a greater penetration in the hair follicle than simple pharmaceutical forms. Liposomes exhibited greater penetration depth than standard formulas. The relative penetration depth used in the standard formula was $30 \%$ on average, while liposomal formulations mainly penetrated to a greater depth of hair follicles. Amphoteric and cationic liposomes reach a depth of relative penetration of about $70 \%$ of the length of the full hair follicle (13).

Transfollicular drug delivery can greatly affect the absorption of steroid drugs. A research showed that this drug delivery method can greatly affect the permeation of drugs, such as hormonal drugs and corticosteroids (14).

In a study that compared the absorption of drugs from the scalp and abdomen, the results showed that the scalp

Copyright (c) 2018, Jundishapur Journal of Natural Pharmaceutical Products. This is an open-access article distributed under the terms of the Creative Commons Attribution-NonCommercial 4.0 International License (http://creativecommons.org/licenses/by-nc/4.0/) which permits copy and redistribute the material just in noncommercial usages, provided the original work is properly cited. 
could be significantly more suitable for the delivery of hydrophilic and lipophilic drugs than abdominal skin. Histological examination of the skin after using the formulation shows that the probe penetrates the site of the skin and follicles (15).

The rate of absorption of caffeine can be greatly increased by crossing the trans-follicular pathway (16). Various absorption enhancers can also greatly enhance the permeability of the drug through the hair follicle. Therefore, the use of oleic acid and eucalyptus increased the absorption of caffeine up to four times, while maintaining caffeine in stratum corneum was the same in all cases. The researchers found that the optimal formulation of drug delivery through the transfollicular route can also be used as absorption enhancers (17).

The findings of the review of transfollicular drug delivery suggest that this drug delivery pathway can be a good route to replace other methods. Formulations used in studies, such as liposome, micro-emulsion, foam and etc. somewhat respond to this pathway more appropriately.

\section{References}

1. Vogt A, McElwee KJ, Blume-Peytavi U. Biology of the hair follicle. In Blume-Peytavi U, Whitting DA, Trueb RM, editors. Hair growth disorder. Berlin, Heidelberg: Springer Berlin Heidelberg; 2008. p. 1-22.

2. Lauer AC, Lieb LM, Ramachandran C, Flynn GL, Weiner ND. Transfollicular drug delivery. Pharm Res. 1995;12(2):179-86. [PubMed: 7784330].

3. Patzelt A, Lademann J. Drug delivery to hair follicles. Expert Opin Drug Deliv. 2013;10(6):787-97. doi: 10.1517/17425247.2013.776038. [PubMed: 23530745].

4. Illel B. Formulation for transfollicular drug administration: some recent advances. Crit Rev Ther Drug Carrier Syst. 1997;14(3):207-19. [PubMed: 9282266].

5. Hansen S, Lehr CM. Transfollicular delivery takes root: the future for vaccine design? Expert Rev Vaccines. 2014;13(1):5-7. doi: 10.1586/14760584.2014.862500. [PubMed: 24428204].
6. Blume-Peytavi U, Massoudy L, Patzelt A, Lademann J, Dietz E, RasulevU, et al. Follicular and percutaneous penetration pathways of topically applied minoxidil foam. Eur J Pharm Biopharm. 2010;76(3):450-3. doi: 10.1016/j.ejpb.2010.06.010. [PubMed: 20600888].

7. Bhatia G, Zhou Y, Banga AK. Adapalene microemulsion for transfollicular drug delivery. J Pharm Sci. 2013;102(8):2622-31. doi: 10.1002/jps.23627. [PubMed: 23728912].

8. Kogan A, Garti N. Microemulsions as transdermal drug delivery vehicles. Adv Colloid Interface Sci. 2006;123-126:369-85. doi: 10.1016/j.cis.2006.05.014. [PubMed: 16843424].

9. Salimi A, Moghimipour E, Tavakolbekhoda N. Transdermal delivery of celecoxib through rat skin from various microemulsions. skin. 2013;8:9.

10. Kreilgaard M, Pedersen EJ, Jaroszewski JW. NMR characterisation and transdermal drug delivery potential of microemulsion systems. JControl Release. 2000;69(3):421-33. [PubMed: 11102682].

11. Escribano E, Calpena AC, Queralt J, Obach R, Domenech J. As sessment of diclofenac permeation with different formulations: anti-inflammatory study of a selected formula. Eur J Pharm Sci. 2003;19(4):203-10. [PubMed:12885384]

12. Moghimipour E, Salimi A, Zadeh BSM. Effect of the various solvents on the in vitro permeability of vitamin b 12 through excised rat skin. Tropic J Pharmaceut Res. 2013;12(5):671-7.

13. Jung S, Otberg N, Thiede G, Richter H, Sterry W, Panzner S, et al. Innovative liposomes as a transfollicular drug delivery system: penetration into porcine hair follicles. J Invest Dermatol. 2006;126(8):1728-32. doi: 10.1038/sj.jid.5700323. [PubMed: 16645589].

14. Hueber F, Schaefer H, Wepierre J. Role of transepidermal and transfollicular routes in percutaneous absorption of steroids: in vitro studies on human skin. Skin Pharmacol. 1994;7(5):237-44. [PubMed: 7519865].

15. Ogiso T, Shiraki T, Okajima K, Tanino T, Iwaki M, Wada T. Transfollicular drug delivery: penetration of drugs through human scalp skin and comparison of penetration between scalp and abdominal skins in vitro. J Drug Target. 2002;10(5):369-78. doi: 10.1080/1061186021000001814. [PubMed: 12442807].

16. Otberg N, Patzelt A, Rasulev U, Hagemeister T, Linscheid $M$, Sinkgraven R, et al. The role of hair follicles in the percutaneous absorption of caffeine. Br J Clin Pharmacol. 2008;65(4):488-92. doi: 10.1111/j.1365-2125.2007.03065.x. [PubMed: 18070215]. [PubMed Central: PMC2291387].

17. Abd E, Benson HAE, Roberts MS, Grice JE. Follicular penetration of caffeine from topically applied nanoemulsion formulations containing penetration enhancers: in vitro human skin studies. Skin Phar macol Physiol. 2018;31(5):252-60. doi: 10.1159/000489857. [PubMed: 30001555] 